\title{
Pelo olhar de Anísio Teixeira, um ensaio sobre educação e nacional-desenvolvimentismo
}

From the perspective of Anísio Teixeira, an essay on education and national developmentalism

\section{LORENA FREITAS*}

Só existirá democracia no Brasil no dia em que se montar no país a máquina que prepara as democracias. Essa máquina é a da escola pública.

Anísio Teixeira

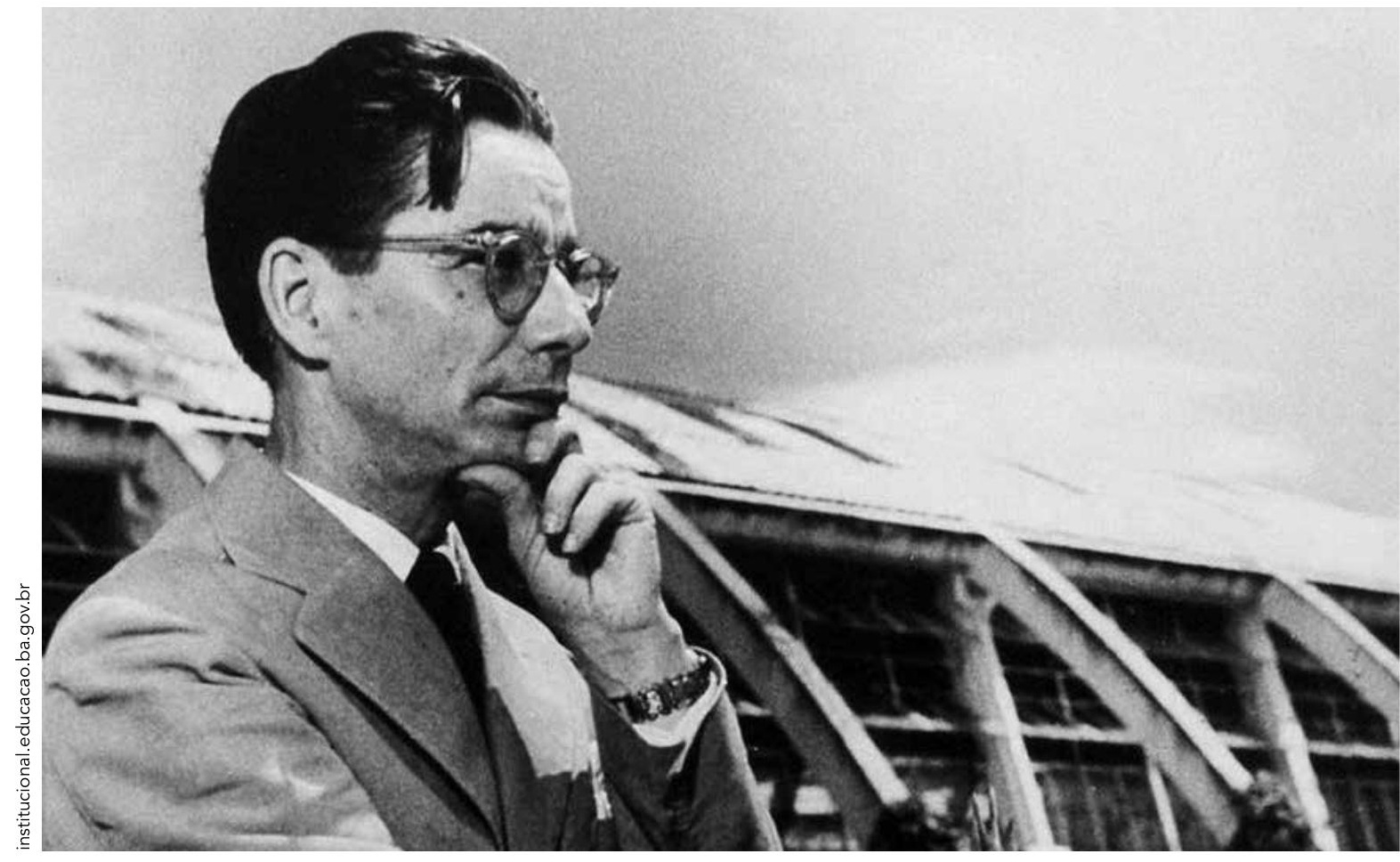

O intelectual brasileiro Anísio Teixeira (1900-1971) 


\section{RESUMO}

O objeto deste ensaio é delimitado no âmbito das ideias anisianas em defesa da educação. $\mathrm{O}$ projeto educacional pensado e executado por Anísio Teixeira ao longo da vida tem inegável inspiração na ideologia isebiana nacional-desenvolvimentista. Assim, exploram-se aqui os argumentos teóricos e projetos executados pelo autor pari passu com exemplos hodiernos que sirvam de teste e fundamentos empíricos. O ensaio reclama a atual oportunidade e urgência do sonho anisiano para a retomada do desenvolvimento nacional.

Palavras-chave: Anísio Teixeira. Nacional-desenvolvimentismo. Educação.

\section{ABSTRACT}

The object of this essay is delimited within the scope of Anísio Teixeira's conceptual framework that support the defense of education. The educational project was designed and executed by Teixeira throughout his lifetime, and it has undeniable national-developmentalist Isebian ideology. Thus, this paper explores the theoretical arguments and projects carried out by Teixeira along with modern examples that serve as test and as empirical foundations. Taking that into account, the essay claims the current opportunity and urgency of Teixeira's dream for the resumption of national development.

Keywords: Anísio Teixeira. National developmentalism. Education. 
O pensamento de Anísio Teixeira tem uma característica peculiar: o absoluto foco na questão da educação. Anísio trabalha a educação como substrato de uma cultura e nisso sofre marcante influência do pragmatismo de Dewey. Assim, este ensaio tem por pressuposto que a educação em Anísio é mais do que simplesmente o processo pedagógico de escolarização, é ao mesmo tempo o "o quê", "o porquê", "o como" e "o para quê".

Em outras palavras, Anísio se debruça sobre as condições necessárias para garantir a escolarização universal, laica e gratuita, mas também para que a educação não seja "mero ornato", desconectada de fins coletivos e nacionais. Assim, há uma natureza descritiva na abordagem e o aceno para conclusões normativas, se assim se puder referir-se

Anísio se debruça sobre as condições necessárias para garantir a escolarização universal, laica e gratuita, mas também para que a educação não seja "mero ornato", desconectada de fins coletivos e nacionais a tal linguagem de segunda ordem que se opera por meio da reflexão sobre as dificuldades e meios de superação da crise da educação com foco no desenvolvimento nacional brasileiro.

Sua defesa da educação ultrapassa a preocupação que em termos jurídicos assenta nos chamados direitos de segunda geração, ou direitos sociais. Anísio concebe o processo educacional como um bem que reflete seu povo, que ao mesmo tempo constrói as condições para que esse povo se desenvolva e que, por tudo isso, deve ser cuidado.

Óbvio que essa concepção anisiana é muito influenciada pela recepção das ideias de Dewey, um dos pioneiros do pragmatismo estadunidense. Mas também é caudatária de uma correta percepção pela qual a aquisição do conhecimento não é apenas modo de ilustração, beletrista e livresco - conhecimento é para implicar melhoria de vida e, socialmente, atuar na formação de quadros técnicos e científicos numa visão estratégica dedicada a garantir independência nacional e desenvolvimento soberano.

Essa atitude "prática" em relação ao conhecimento, que requer projeto e planejamento de desenvolvimento não subordinado, almeja a formação de quadros científicos nacionais. Por isso mesmo é que já em 1952 Anísio saudava a revolução

\footnotetext{
Anísio vai analisar, sendo seu incansável oponente, um sistema excludente que se caracteriza como uma "educação popular mínima para todos e uma pós-primária para alguns. E os alguns, salvo os das poucas escolas públicas e gratuitas desse nível [ou alvos da caridade religiosa], eram os das classes abastadas ou semiabastadas." (TEIXEIRA, 2005, p. 209)
} 


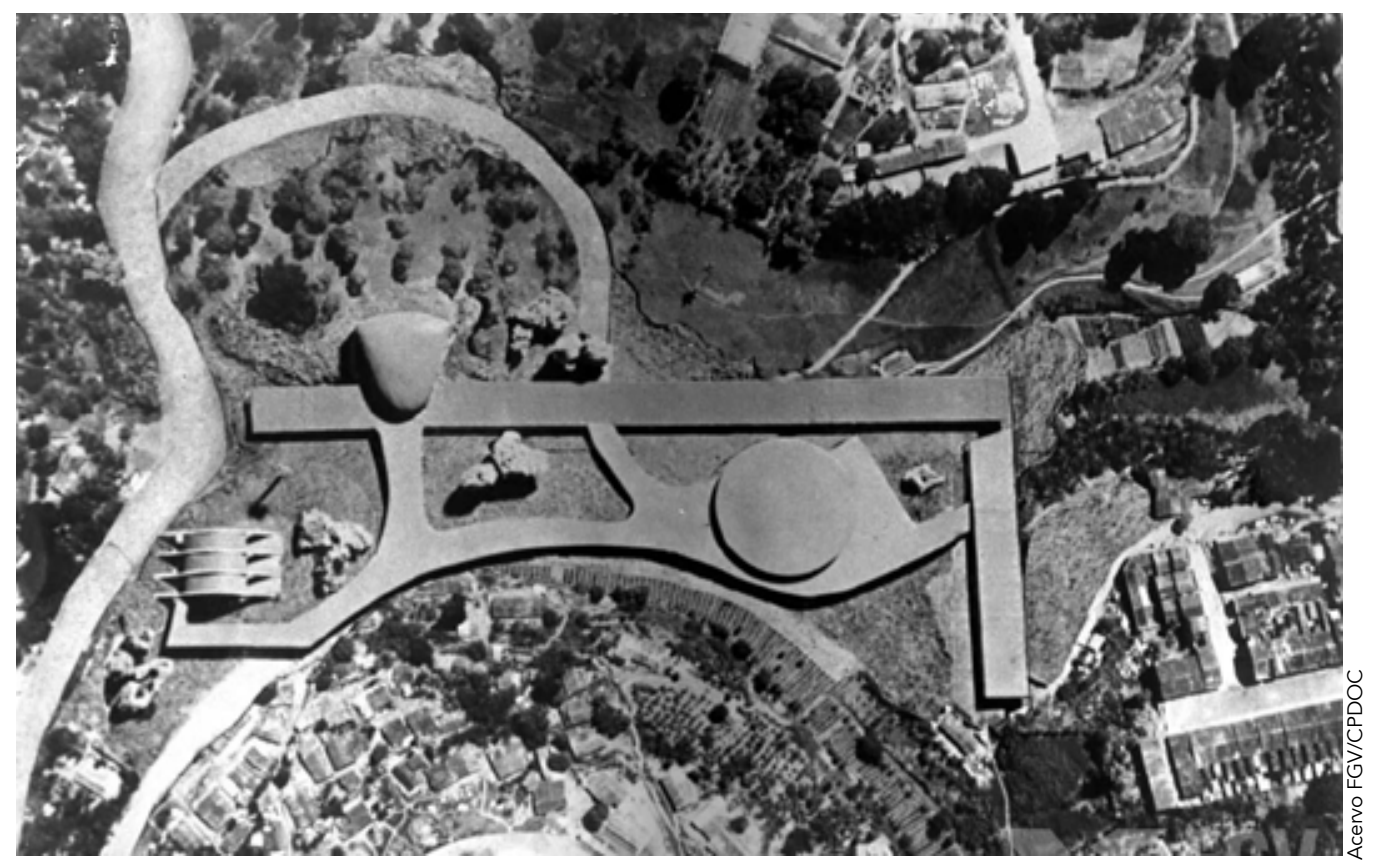

Das muitas realizações de Anísio Teixeira, a Escola Parque, ou Centro Educacional Carneiro Ribeiro, em Salvador, Bahia, foi a que alcançou maior repercussão no Brasil e em diversos outros países

brasileira lembrando a relevância de passos e etapas inevitáveis em um processo de afirmação do progresso (TEIXEIRA, I977, p. 29-3I).

É por esse prisma do pensamento anisiano que o ensaio se lança na argumentação e reflexão sobre a defesa anisiana da educação como patrimônio cultural (FREITAS; CECATO, 20I7, p. 267). É certo que esse exato termo para definir educação não se localiza no seu pensamento, até onde esta investigação foi ${ }^{2}$, mas como ensaio se pode experimentar a reflexão nessa dimensão heurística. É patrimônio cultural pelo intrínseco foco voltado para o desenvolvimento nacional.

A forma-ensaio, como "um pequeno texto formal sobre um assunto específico" (ESSAY, 1999, tradução nossa), é aqui empregada com referência clássica em David Hume e Adam Smith, e eis que persegue as características da liberdade e da variedade às quais Hume recorre sem dispensar a unidade. A síntese da proposta ensaística perpassaria a "perspicuidade de estilo" de que fala Smith nas primeiras linhas da sua segunda conferência sobre retórica e belas-letras (SMITH, 2008, p. 79), mas centralmente tal liberdade estaria em ser "um gênero que tem a conversa por modelo" (SUZUKI, 20II, p. 319).

A liberdade aqui se situa na reflexão desagrilhoada de conclusões, do que decorre a característica da variedade. Esta por sua vez está no fluxo discursivo em oposição ao espírito monotemático no sentido de "lucubrações detidas e extenuantes

\footnotetext{
O não uso do termo patrimônio cultural não elide a presença da ideia. Serve de exemplo o trecho, entre outros, em que Anísio toma por empréstimo a questão da cultura para fiar a tese da democracia e da igualdade de condições: "Uma nação ou um povo é a expressão de sua cultura e essa cultura será tanto mais una, homogênea e inteiriça quanto mais simples." (TEIXEIRA, 2005, p. 65)
} 
sobre um assunto só" (SUZUKI, 20II, p. 315), todavia não significando nem implicando dispersão. A unidade como característica é abordada por Hume quando diz que

mesmo em nossos sonhos diurnos e noturnos mais loucos, descobriremos, se pensarmos sobre isso, que a imaginação não é totalmente selvagem, e que mesmo na imaginação as diferentes ideias se sucedem de uma forma um tanto regular. Se a conversa mais solta e mais livre fosse escrita, você seria capaz de ver algo que a mantém unida em todas as suas voltas e reviravoltas. Ou, se não, a pessoa que quebrou o fio pode dizer que foi gradualmente afastada do assunto da conversa por alguma linha de pensamento ordenada que estava silenciosamente acontecendo em sua mente (HUME, 20I7, p. Io, tradução nossa).

Justificamos, por fim, que o estilo³ não abdica de um encadeamento argumentativo, apenas se faz (ou se pretende) mais singular e conciso, trazendo ilustrações da realidade como simples exemplos, carentes de maior investigação em sede de outra pesquisa e artigo ${ }^{4}$.

Ainda que recorra à estrutura ensaística livre de sumário, mantém a pontuação de três partes, sendo que a primeira e a derradeira fazem as vezes de introdução e conclusão, de maneira que a segunda seção desenvolve algumas teses de Anísio e explora delas algumas consequências práticas.

Nessa segunda parte, as temáticas são destacadas em itálico, todavia considerando que são temas que dialogam entre si e se conectam; tais aparecem em mais de um momento do trabalho, e eis que o roteiro básico escolhido foi o de seguir a biografia de Anísio, e, naquilo que tem de produção ou debate em cada tempo, o ensaio entra com as digressões argumentativas. A opção de se guiar pela cronologia de vida e obra serviu também à guisa de delimitação do quadro teórico do ensaio. Eis que destacamos os acontecimentos e textos com base nos temas que os vinculam, e para tudo, o fio condutor está na identificação em Anísio da defesa da educação como o trabalho de uma vida 5 .

Explicada a forma, adiante-se o desenvolvimento.

\section{2}

Anísio Spínola Teixeira foi um baiano nascido em I90o que fez Direito no Rio de Janeiro. Em 1924 assume a função de inspetor-geral de ensino da Bahia por convite do governador Góes Calmon, e assim passa a trabalhar com a educação. Data dessa

Sobre Hume e as características do ensaio, ver Freitas e Feitosa (2017, p. 1-2)

"Os leitores irão apreender mais prontamente uma cadeia de raciocínio, que é mais simples e concisa, em que as proposições principais apenas estão ligadas umas às outras, ilustradas por alguns exemplos simples e confirmadas por alguns dos argumentos mais convincentes." (HUME, 2010, p. 26, tradução nossa)

Para um perfil pessoal e intelectual de Anísio Teixeira, ver o "ensaio" de abertura, sob o título "A trajetória de Anísio Teixeira", de autoria de Clarice Nunes (NUNES, 2010, p. 11-60). Importa destacar e ampliar divulgação do site da Biblioteca Virtual Anísio Teixeira, <http://www.bvanisioteixeira.ufba.br/ index.html>, referência para esta parte. 
época (1924) seu primeiro artigo sobre o tema ("A propósito da escola única"), sob referência da obra Méthodes américaines d'éducation générale et technique, de Omer Buyse. O artigo já traz tema que vai ser objeto de sua bandeira de luta, uma escola pública, gratuita e universal:

Uma "escola única" obrigatória para todos, ministrando ensino de um modo integral e uniforme, seria o aparelho mágico destinado a dar a todos os homens o pleno desenvolvimento de suas faculdades. A perfeita unidade da cultura e o seu perfeito desenvolvimento criariam a perfeita unidade e a perfeita grandeza nacionais. Tal edifício grandioso e simples de instrução abriria para esse país privilegiado o maior caminho de todos os tempos para a república, para a democracia (TEIXEIRA, 1924, p. I).

O contexto de um sistema educacional sem reconhecimento social e que necessitava ser constituído no país o força a ir (ano de 1925) conhecer a experiência da educação na Europa e resulta no projeto de lei para a reforma do ensino baiano, sancionado na forma da lei $\mathrm{n}^{\circ}$ I.846, de I4 de agosto de 1925 . Em 1927 viaja para os Estados Unidos, e as impressões daquela experiência educacional se veem na obra de 1928, "Aspectos americanos de educação", já sob influência de John Dewey (TEIXEIRA, 1959; TEIXEIRA, I955, uma referência clássica do pragmatismo filosófico, de quem seria aluno nesse mesmo ano na Universidade de Columbia, onde se torna colega de Gilberto Freyre e se pós-gradua em 1928.

Retornando mestre ao Brasil em 1929, não consegue adesão do então governador da Bahia para implementar suas ideias de mudanças, razão por que se demite e passa para o magistério de Filosofia e História da Educação da Escola Normal de Salvador, além de publicar no ano seguinte a primeira tradução para o português de dois trabalhos de Dewey. Esse estudo serviu para a publicação do artigo "Escola nova" no 'Boletim da Associação Bahiana de Educação'.

Ele faz uma análise contrapontística da velha escola com a escola nova, no que fundamenta esta sob a rubrica de que, nas palavras de Anísio,

nós temos que, graças ao desenvolvimento da ciência e sua aplicação à vida humana, entramos em uma fase de movimento e de transformação continua. Não só as condições materiais da vida mudam dia a dia, como sobretudo a visão do homem sobre a vida. Nesse aspecto, ressalta hoje acima de qualquer outro, o seu desapego aos velhos sistemas autoritários do passado, sejam eles tradicionais ou religiosos. (TEIXEIRA, 1930, p.3).

Sob a rubrica desse paralelo comparativo, reforçando sua tese e fio condutor de toda a sua obra e vida, a educação pública, gratuita e universal, Anísio diz que "não se pode, com efeito, discutir educação como algo em si mesmo. Nada mais ela é do que epifenômeno de forças muito mais profundas, que controlam a sociedade." E complementa: "toda fase de transição é fase de luta entre o velho e o novo, e a arte de 
conduzir tais batalhas, extremamente difícil, em virtude das contradições que gera o próprio processo revolucionário de transformação" (TEIXEIRA, I96I, p. 92, 7I).

É de suma importância no cenário nacional o peso desse intelectual na reconstrução do sistema educacional, mesmo porque sua bandeira ainda é objeto de luta diuturna. Todavia, o contexto da educação nos fins da década de 1920 sobremaneira exigia esforço para garantir reconhecimento social para a educação (SAVIANI, 2007, p. 2I8).

O reconhecimento do valor da educação como condição necessária para o desenvolvimento nacional ${ }^{6}$ vai estar presente em várias reflexões de Anísio, além de ser comum a outros pensadores (como os demais signatários do "Manifesto dos pioneiros da educação nova" ou mesmo os isebianos). No caso de Anísio, seu prestígio como pedagogo não o faz pensar a educação de forma ensimesmada; eis que reclama como necessário "realizar simultaneamente as 'reformas de base', inclusive a reforma agrária, e o sistema universal de educação que não chegamos a construir até hoje, já no meado do século XX" (TEIXEIRA, 20II, p. 30).

Se a educação é para desenvolver a nação, necessário se fez, em sua época e na concepção anisiana, romper com os vícios arraigados, que criaram o dualismo da escola velha com a escola nova. Aquela representa o "ensino-ornamento ou livresco", pois assim Anísio caracterizava o ensino brasileiro na sua maioria, porque era um ensino voltado para que os filhos dos educados continuassem sendo educados, garantindo o status quo, assim como os não educados ("que trabalhavam e não precisavam se educar") continuassem desprovidos de desenvolver suas potencialidades (TEIXEIRA, 20II, p. 3I).

Observe que a ironia que a acuidade anisiana consegue captar é que o ensino, mesmo para as camadas mais abastadas, "era para ilustrar nas artes de falar e escrever", de forma que não estava engendrada como processo de preparação real para as diversas modalidades da vida moderna (TEIXEIRA, 20II, p. 3I). Assim, usa a contraposição entre escola velha e nova para mostrar que um profundo nacionalismo, para além da defesa do país contra inimigos externos, é sobretudo "um movimento de consciência da nação contra a divisão, o parcelamento de seus filhos entre "favorecidos" e "desfavorecidos" e contra a alienação de sua cultura e de seus gostos. Só a escola pública poderá mostrar-nos o caminho da emancipação nacional" (TEIXEIRA, I960, p. 208). Na década de I930, Anísio vai para o Rio de Janeiro, então capital da

\footnotetext{
Sobre o investimento na educação e suas consequências reais no desenvolvimento nacional, temos tanto a referência até de economistas liberais no que se refere a países como Japão e Coreia do Sul quanto as experiências de economistas das mais diversas tendências, mas que têm em comum preocupações sociais, de natureza emancipatória, como é o caso, na América Latina, dos cepalinos e dos teóricos da dependência. Sobre a posição de um economista liberal, Douglas North, contrário a Celso Furtado no que toca a um projeto para a Sudene: "No Five-Year Plan [Plano Quinquenal da Sudene] há uma seção voltada para o ensino técnico-científico, mas a ênfase recai no desenvolvimento do ensino superior. North reconhece os méritos desse ponto, mas é cético [quanto a] que tais investimentos tenham retorno sem que os problemas das universidades localizadas no Nordeste fossem superados antes. North afirma que ganhos de produtividade podem advir também da qualidade dos fatores de produção e que não havia naquele plano quinquenal propostas para promover a educação básica no Nordeste. Ele aponta que isso seria uma falha do plano." (BOIANOVSKY; MONASTERIO, 2017, p. 23, grifos nossos)
} 
amadurecimento da reflexão

anisiana tem

consubstanciação com as temáticas da democracia e do nacionalismo

\section{$\underline{x+5}$}

MANIFESTO

DOS PIONEIROS

DA EDUCAÇÃO NOVA

(1932)

E DOS EDUCADORES

(1959)
Capa do Manifesto dos pioneiros da educação nova (1932) e dos educadores (1959)

República, e assume a Diretoria da Instrução Pública do Distrito Federal. Suas ideias encontram maior apoio de outros intelectuais, do que é exemplo "O manifesto dos pioneiros da educação nova", do qual é signatário, em que se lê:

do direito de cada indivíduo a sua educação integral decorre logicamente para o Estado que o reconhece e o proclama o dever de considerar a educação, na variedade de seus graus e manifestações, como uma função social e eminentemente pública, que ele é chamado a realizar, com a cooperação de todas as instituições sociais (AZEVEDO, 202I, p. 43).

Acentuado como se expressa no manifesto o caráter de direito social da educação, logo, de dever do Estado, redunda que tal contexto vai se evidenciar na sua produção, que acresce ao tema da educação, no tocante a questionar o que e como, os problemas do porquê e para quê. Em outros termos, o amadurecimento da reflexão anisiana tem consubstanciação com as temáticas da democracia e do nacionalismo. Esse manifesto não só destaca o papel de Anísio como o torna pessoa não quista entre os educadores católicos, contrários, em especial, à educação pública e gratuita. Esse desacordo fica à espreita até i958, quando retoma fôlego com o "Memorial dos bispos gaúchos" ao presidente J. Kubitschek sobre a escola pública única.

A correlação entre a defesa da educação e a democracia em Anísio Teixeira é presente em toda a sua vida, marcadamente quando assume a educação no seu período principal de constituição como sistema educacional (TEIXEIRA, I97I, p. I2-37; TEIXEIRA, I973, p. 57-59). Não é à toa que, sem ignorar uma questão central da educação - o postulado democrático —, nosso educador compreendia que tal proposição é fundamento, pressuposto, porta de entrada, mas que, por si só, não garante os resultados de antemão, pois o papel da educação, pode muito, mas não pode tudo, sob pena de levar à ilusão (ideológica) de que tudo decorre apenas da aquisição de conhecimento escolar. Ora, se não pode ser ignorado que a educação formal é central em qualquer processo de emancipação, ela não é o decisivo, visto que emancipação é, centralmente, uma alteração nas estruturas de poder, no nosso caso, a alteração de 
um modelo antipátria e antipovo para uma democracia de caráter não apenas institucional, mas também no âmbito material. Ou seja, embora seja um fator da maior importância, sozinha, a atividade educacional não altera estruturas, não é o elemento decisivo, em última instância, visto que a vida social se resolve positivamente pela alteração das estruturas de espoliação das classes, dos povos e nações (TEIXEIRA, 2006, p. 253-254, 258-259).

Essa visão contemporânea da educação foi uma característica saliente da postura anisiana e acabou por atrair uma significativa legião de admiradores e discípulos, que se evidencia, entre tantos outros exemplos, num rico depoimento sobre Anísio, dado pelo recém-falecido dirigente político Haroldo Lima, que o evocava ao final dos anos I950, mostrando a influência progressista e inovadora que o ideário educacional de Anísio exerceu sobre a juventude. Haroldo relata que, ainda vestibulando em Salvador - convidado que foi para uma palestra hostilizada pelas instituições religiosas, que se colocavam contra o projeto inovador anisiano para a educação -, propôs ao diretor da escola em que então estudava, em Salvador, que lhe fosse permitido estabelecer um contraditório com as críticas dirigidas ao seu parente, Anísio Teixeira (Anísio era tio dele, pelo lado paterno):

Comprei os livros que havia de Anísio. Em particular, comprei Educação não é privilégio, e mais uns dois ou três. Todos os que havia na livraria Civilização Brasileira, na rua Chile, em Salvador [...]. Fui para casa, e o primeiro que peguei, me debrucei [sobre ele]. E aí é curioso, porque quando terminei de ler o livro, eu era um cara assim, anisiano, consciente e de esquerda. O que me trouxe para a esquerda foi aquele livro (LIMA, 2020, p. I5).

Por sua vez, ressalta o professor Mamede Said que "com uma destacada atuação no período que vai de 1920 a I97I, ano de sua morte, a vida de Anísio foi toda ela dedicada à causa da democratização da educação e da modernização dos métodos pedagógicos" (SAID, 20I8, p. II). Para Anísio, a educação era condição sine qua non para a construção da democracia (SAID, 20I8, p. I4). Tal tema é central no discurso de I947, na condição de secretário de Educação na Bahia, diz:

A democracia depende de se fazer do filho do homem - graças ao seu incomparável poder de aprendizagem — não um bicho ensinado, mas um homem. Assim, embora todos os regimes dependam da educação, a democracia depende da mais difícil das educações e da maior quantidade de educação. Há educação e educação. Há educação que é treino, que é domesticação. E há educação que é a formação do homem livre e sábio. Há educação para alguns e há educação para todos. A democracia é o regime da mais difícil das educações, a educação pela qual o homem, todos os homens e todas as mulheres aprendem a ser livres, bons e capazes. Nesse regime, pois, a educação, faz-se o processo mesmo de sua realização. Nascemos desiguais e nascemos ignorantes, isto é, escravos. A educação faz-nos livres pelo conhecimento e 


\section{Assim como Teixeira, uma geração}

\section{de intelectuais cuja preocupação}

maior, na primeira metade do século

XX, foi a de organizar a nação e

forjar o povo através da defesa da

cultura nacional-popular, objetivava

assegurar a unidade nacional pela

via de uma educação de caráter

claramente público e pela construção

de um campo de luta cultural a partir

mesmo da própria universidade

pelo saber e iguais pela capacidade de desenvolver ao máximo os nossos poderes inatos. A justiça social, por excelência, da democracia consiste nessa conquista de igualdade de oportunidade pela educação (TEIXEIRA, I947, p. 89-90).

Ao tempo que analisa as condições para a educação democrática criticando a desigualdade no ensino, ele aponta mais um aspecto dessa condição desigual em 1932 ao afirmar que o divórcio entre o ensino primário e profissional e o ensino secundário e superior concorre para que se estabeleçam no Brasil dois sistemas escolares paralelos, fechados em compartimentos estanques e incomunicáveis, instrumentos de uma estratificação social, por tudo, antidemocrática.

Uma educação democrática capacitaria os indivíduos para a reconstrução do país. Anísio acentuava que a forma democrática está na participação de todos na formação da sociedade, o que implica o desenvolvimento de cada um até o máximo de suas possibilidades e o enriquecimento do pensamento individual (TEIXEIRA, 2009, p. 39).

Assim como Teixeira, uma geração de intelectuais cuja preocupação maior, na primeira metade do século XX, foi a de organizar a nação e forjar o povo através da defesa da cultura nacional-popular, objetivava assegurar a unidade nacional pela via de uma educação de caráter claramente público e pela construção de um campo de luta cultural a partir mesmo da própria universidade. 
E isso se deu pelo motivo de que começa, naquele período, a ser gestado um processo de amadurecimento proporcionado por um novo cenário no qual as classes definem seus campos e passam a mobilizar-se pelos seus interesses. E é nessa nova configuração que aparece o problema do nacionalismo, um novo cenário sobre o qual os isebianos, dentre eles Werneck Sodré, terão de se debruçar.

"Por que nacionalismo?", indaga Sodré. E ele mesmo responde: "porque, agora, são as forças econômicas externas o mais poderoso obstáculo ao nosso desenvolvimento, e os seus aliados internos declinam em resistência e já não podem tutelar o país" (SODRÉ, 202I, p. I43-I6I)

Dessa geração não se pode passar sem comentar um seu contemporâneo, e a ele bastante ligado, Álvaro Vieira Pinto, outro gigante um tanto esquecido no debate hodierno e fortemente influenciado pela ontologia existencialista, que sobre o trabalho científico assegurava que ele só adquire inteligibilidade e sentido "quando se parte do postulado original da existência humana enquanto modo de ser de um animal que deve conquistar os seus meios de subsistência pelo domínio crescente das condições do ambiente em que vive [..., e que] o trabalho científico não passa de um caso particular do trabalho geral que a sociedade executa a fim de se desenvolver" (PINTO, I969, p. 245, 325) ${ }^{8}$.

A preocupação com o papel da ciência é o foco de Ciência e humanismo, em que aborda características das ciências em oposição a outras formas de conhecimento, chegando mesmo a concluir que hoje vivemos com a verdade "já não dupla, como a que a Igreja contestou em I5I8, mas uma tripla [verdades científicas, filosóficas e religiosas]" (TEIXEIRA, 2005, p. I45). Assim, preserva sua fé, que quase o faz virar padre, sendo "salvo" pela filosofia ao estudar com Dewey. No campo epistemológico, aprofunda a discussão sobre processo de conhecimento através da troca de correspondências com Maurício da Rocha e Silva (biólogo e professor da UnB), e aí se nota também a influência do pragmatista estadunidense.

Um episódio real, citado pelo filho de Anísio - Carlos Teixeira - sobre comentários que o pai fazia, sintetiza empiricamente a reflexão de Álvaro sobre progresso técnico-científico e as consequências práticas que extrai de Dewey. $\mathrm{O}$ trecho é: "Uma das coisas que me irrita e me indigna é realmente a gente promover uma educação pela qual eu sou capaz de ensinar todos os nomes de geladeiras, toda a história da geladeira e não ensinar como funciona a geladeira." (EDUCADORES, 2007)

O contato citado com a obra do educador John Dewey, iniciado durante a década de 1920, proporcionou a Anísio Teixeira a possibilidade de construir um novo significado existencial, de encontrar resposta programática para as questões

Temos aí as tensões típicas de uma situação de disputa aberta: os "de cima" já não podem mandar como antes e os "de baixo" já não aceitam mais os padrões anteriores de dominação.

Os aportes, neste texto, sobre as conexões entre os pensamentos de Anísio Teixeira e Álvaro Vieira Pinto são resultantes de debates com o colega professor Enoque Feitosa, que cita Vieira Pinto, para quem, não obstante, o enorme progresso técnico-científico (e isso ele percebia numa obra escrita entre 1973 e 1974) não se pode conciliar com os equívocos a respeito do destino do ser humano, visto que sempre terá pertinência a questão "quem produz o produtor?" (FEITOSA, 2018, p. 28; PINTO, 2005, p. 709-717). 
educacionais com as quais estava lidando e de elaborar uma síntese para uma nova visão de mundo.

Como mencionado por Nunes (2000, p. I4, ss.), "sua apropriação de Dewey foi longa e múltipla", e tal autor "lhe permitiu notável abertura para o mundo moderno", proporcionando a ele um modelo que acabou por fornecer um referencial teórico que se somou ao combate da improvisação e do autodidatismo então reinante, abrindo a possibilidade de operacionalizar uma política e criar a pesquisa educacional no país.

Anísio Teixeira não assimilou Dewey incondicionalmente, como enfatiza Nunes, pois, "ao contrário de Dewey, que em nenhum momento indicou, na sua vasta obra, quaisquer medidas de aferição de inteligência ou de escolaridade, Anísio Teixeira aplicou-as nas escolas da rede pública, na década de 1930", e, "se Dewey permaneceu como pensador independente, não se filiando a qualquer partido, Anísio Teixeira chegou até a redigir um programa partidário. Se Dewey nunca entrou na polêmica entre escola confessional e escola pública, Anísio Teixeira mergulhou, em cheio, nela." (NUNES, 20I6)

Já um autor da tradição marxista, Gramsci, quando trata da organização da escola como parte da organização da cultura, preocupara-se com o problema da divisão da escola em "clássica" e profissional — um dos eixos centrais da reflexão anisiana. Para o pensador sardo, na civilização moderna, todas as atividades práticas se tornaram tão complexas e as ciências se mesclaram de tal forma à vida que se colocou em xeque o próprio ideário da chamada escola humanista "fundada na tradição greco-romana", e "a tendência hoje [e Gramsci já percebia isso no primeiro quarto do século passado] é a abolição completa de qualquer modelo de escola "desinteressada" (GRAMSCI, I968a, p. II7-I28; FEITOSA, 2008, p. 307).

Anísio, ao seu tempo e na absorção crítica de Dewey, conforme se viu acima, teve a mesma percepção no que concerne à formação de uma comunidade científica nacional não apenas por nascimento, mas fundamentalmente por seus compromissos com o povo, ou seja, nacional-popular', o que implica, para os fins propostos no presente ensaio, uma completa ressignificação e ampliação do conceito não apenas de cultura como de patrimônio cultural a que se deve proteger.

O trabalho de Anísio no antigo distrito federal o projeta nacionalmente por ter criado uma rede municipal de ensino da escola primária à universidade (UDF), além de introduzir uma moderna arquitetura escolar, com escolas amplas e espaços específicos para várias atividades, como as manuais, de educação física e de artes, além das intelectuais (bibliotecas e laboratórios). Também ampliou as matrículas, criou os servi-

Para o conceito de nacional-popular, visto que em muitas línguas ambos os termos têm convergência semântica e pragmática, ver Gramsci (1968b, p. 103-110). 
ços de extensão e aperfeiçoamento, as escolas técnicas secundárias e transformou a antiga escola normal em instituto de educação. Essa plataforma de educação integral anisiana quer formar um cidadão culturalmente vinculado à nação ${ }^{\mathrm{Io}}$, artífice de seu desenvolvimento (tanto o pessoal quanto o do país) ${ }^{\mathrm{II}}$.

Em razão de ter sido perseguido politicamente ${ }^{\mathrm{I} 2}$, sob a alegação de ser da Intentona Comunista, de ser da Aliança Nacional Libertadora (ANL), ele se exila (I93745) na sua terra natal, interior da Bahia, onde incursiona pelo extrativismo mineral e logra êxito explorando manganês. Em 1945 retorna à capital da Bahia como secretário de educação e saúde do Estado, e em 1946 aceita o convite e vira primeiro-secretário executivo da Organização das Nações Unidas para a Educação, a Ciência e a Cultura (Unesco).

A Escola-Parque em Salvador é uma das referências do trabalho de Anísio na realidade concreta, como é o cerne de sua obra; casamento entre teoria e prática, essa

10 A proposta anisiana pretende criar as condições para superar as deficiências do "complexo colonial" que se vincula à ideia de dependência. Como diz Navarro: "O conceito de dependência, no interior da obra do Iseb, é utilizado para definir tanto a situação colonial como a de subdesenvolvimento ou semicolonialismo." (TOLEDO, 1997, p. 83)

11 A integração de educação (teoria e prática), arquitetura e desenvolvimento nacional, como elementos centrais do pensamento de Anísio, é a própria integração dos elementos que compõem a ideia de patrimônio cultural da Constituição Federal (que Anísio não viveu para ver). E mesmo que se perceba a presença desses elementos no conceito normativo, longe está essa norma de uma real concretização. Assim, leia-se o texto constitucional no seu artigo 216: "Constituem patrimônio cultural brasileiro os bens de natureza material e imaterial, tomados individualmente ou em conjunto, portadores de referência à identidade, à ação, à memória dos diferentes grupos formadores da sociedade brasileira, nos quais se incluem: I — as formas de expressão; II — os modos de criar, fazer e viver; III — as criações científicas, artísticas e tecnológicas; IV — as obras, objetos, documentos, edificações e demais espaços destinados às manifestações artístico-culturais; V — os conjuntos urbanos e sítios de valor histórico, paisagístico, artístico, arqueológico, paleontológico, ecológico e científico. $\S 1^{\circ}-\bigcirc$ poder público, com a colaboração da comunidade, promoverá e protegerá o patrimônio cultural brasileiro, por meio de inventários, registros, vigilância, tombamento e desapropriação, e de outras formas de acautelamento e preservação. $\S 2^{\circ}$ - Cabem à administração pública, na forma da lei, a gestão da documentação governamental e as providências para franquear sua consulta a quantos dela necessitem. $\S 3^{\circ}-\mathrm{A}$ lei estabelecerá incentivos para a produção e o conhecimento de bens e valores culturais." (BRASIL, 1988) Não obstante as eloquentes argumentações oriundas do texto constitucional, nosso Estado não é tomado, em regra, pela disposição de viabilizar a ampla proteção da produção teórica e intelectual dos que pensaram a ciência e cultura nacionais enquanto instrumentos de emancipação, ou seja, a falta de proteção da produção teórica nacional enquanto instrumento de formação de uma cultura própria é a própria desconsideração de todos os incisos a um só tempo.

12 Sobre as impressões de Anísio Teixeira acerca de Getúlio Vargas, importa notar que, na dedicatória que Anísio fez a Monteiro Lobato de sua obra Educação no Brasil, fica nítido seu sentimento quando afirma: "no último período da grande frustração nacional que foi a Revolução de [19]30, nem sua literatura infantil conseguiu vencer a amargura cívica". Adiante, Anísio reafirma: "também o Brasil vivia seu período máximo de enfaro com o desgoverno nacional" (TEIXEIRA, 2011, p. 23). Interessante notarmos que - e isso tem sido objeto de outros estudos nossos — sua aproximação da ideologia do Iseb não foi suficiente para tirar-lhe a rejeição ao governo de Getúlio Vargas nem para reconhecer o projeto nacionalista deste, em razão da perseguição sofrida, bem como pela destruição de seu projeto educacional em andamento no Rio de Janeiro durante esse governo. Clarice Nunes, respeitada biógrafa, não cita diretamente a perseguição sofrida por Anísio, mas chama a atenção para o fato de que, "à medida que, em meados dos anos 1930, a modernização autoritária se firmou, Anísio Teixeira catalisou a perseguição de católicos e pensadores autoritários. Sua gestão foi avaliada como uma estratégia de oposição dentro da estratégia oficial e, como tal, foi combatida e interrompida. [...] Venceu o projeto repartido de educação: para o povo, uma educação destinada ao trabalho, e para as elites, uma educação para usufruir e exercer a cultura." (NUNES, 2000, p. 24-25). Carlos Teixeira, filho de Anísio, em um documentário diz que, frente às perseguições que recebia, fruto de ser tido como comunista, o pai brincava que ali estava um sistema educacional que ele não conhecia e precisava conhecer (EDUCADORES, 2007). 
escola amplia aquelas marcas já destacadas por bem-sucedidas na rede municipal do Rio de Janeiro. Desse casamento, a questão da administração pública é como a fotografia com suas duas figuras: sua gestão (supracitada) e seus textos (por todos, Educação para a democracia: introdução à administração educacional).

Sua luta pela educação popular, sobremaneira testada e aprovada do ponto de vista dos resultados sociais, lança-o em I95I para o novo distrito federal, Brasília, quando cria a Capes. Essa experiência vem exemplificar seu conceito de educação integral, ou seja, pode-se concluir que tal conceito presente nos escritos sobre a educação básica ganha reflexos para pensar a educação continuada por um olhar com preocupação nacional e desenvolvimentista. Tal olhar formata a estrutura da Capes, para viabilizar o apoio necessário para a expansão da pós-graduação no país. Esse apoio decisivo implicava as condições materiais proporcionadas para formar os posteriores formadores nacionais. Então, financiando a pesquisa (bolsas para formação no exterior) se construiriam as condições de passar a formar com qualidade e quantidade a pós-graduação nacional, que também aperfeiçoaria a educação básica.

A Capes (Coordenação de Aperfeiçoamento de Pessoal de Nível Superior) é uma fundação, vinculada ao Ministério da Educação e Cultura (MEC), que tem como objetivo promover a expansão e consolidação dos cursos de pós-graduação stricto sensu no país. A inspiração de Teixeira para a criação da nova Capes (a sigla vem da já existente Campanha de Aperfeiçoamento) tem pressupostos tanto nas suas ideias sobre bens culturais - a educação seria esse bem primeiro para viabilizar o próprio crescimento nacional (TEIXEIRA, I956a, p. I45-I49) — como na gestão da administração pública - a educação como sistema não pode ser refém de diretrizes centralizadas de gestão do governo que não têm capacidade de perceber as múltiplas variedades e realidades distintas ${ }^{13}$, regionais e locais (TEIXEIRA, I956b, p. 3-23; 1973, p. 57-59; 1967, p. 55-67).

No ano seguinte, acumula a presidência da Capes com a direção do Inep (Instituto Nacional de Estudos e Pesquisas Educacionais Anísio Teixeira - como hoje é intitulado, homenageando-o). A sua origem está vinculada ao CBPE (Centro Brasileiro de Pesquisas Educacionais), criado por Anísio Teixeira em I955 (INEP, s.d.), que se especializou na produção de pesquisas educacionais em todas as regiões do Brasil e promoveu cursos para treinamento de docentes. Observe que aí se evidencia a proposta da educação integral, que integra também educação básica e superior. Tal

13 A variedade local é objeto de sua atenção com a criação dos centros regionais de pesquisas educacionais (CRPEs), vinculados ao Centro Brasileiro de Pesquisas Educacionais (CBPE) e refletindo sua capacidade de articulação, convergência e senso de realidade. Não se pode deixar de mencionar que Gilberto Freyre foi escolhido por Anísio para a direção da CRPE-PE. 
proposta está na plataforma da criação da Capes, nas dez metas, tendo sido em boa medida "esquecida" pelo SNPG (Sistema Nacional de Pós-Graduação) ${ }^{14}$.

Ainda na capital, o antigo sonho da Universidade Nacional (outrora fora a UDF, que resistiu de 1935 a 1939) revive na companhia de Darcy Ribeiro, virando realidade em I96I com a UnB. Era então reitor da UnB em I964 quando o golpe o retira do posto (COMISSÃO..., 20I5). Com o cenário adverso, fica como visiting professor de I964 a I966 nos EUA (em I964, na Columbia University, em I965, na New York University, e em I966, na University of California), onde curiosamente não era considerado comunista, diferentemente da opinião do então governo brasileiro.

De I967 a I969, no Brasil, trabalha em suas obras até que em I97I é encontrado morto no fosso de um elevador, morte inexplicada oficialmente. As suspeitas de que teria sido morto pelo regime, fundadas em perícias e testemunhos, encontram respaldo no Relatório da Comissão Anísio Teixeira de Memória e Verdade da UnB (COMISSÃO..., 20I5), mas restam formalmente incertos os fatos que provocaram sua morte.

Não obstante ter "caído no poço de um elevador" e morrido, seus óculos continuaram íntegros. Morreu por causa de suas lentes, de como suas lentes viam o mundo. Foi a essas lentes que o ensaio recorreu.

\section{3}

Em sede de conclusão, a atualidade de Anísio está desde logo vinculada à urgência do hoje, da crise social e educacional do Brasil hodierno, pois que padece incompleta a concretização de seu sonho: uma educação pública, universal e gratuita que forme cidadãos para o mundo.

Se usarmos as lentes de Anísio, esses três pontos inarredáveis estão em evidência, e daí todo o edifício teórico e a história de sua vida se constroem. Pelo olhar de Anísio, a (re)construção da educação nacional - um patrimônio cultural pelo aceno antropológico, histórico etc. - se esteia no fito da democracia e do nacionaldesenvolvimentismo.

Tylor diz da cultura: "É aquele todo complexo que inclui conhecimento, crenças, arte, lei, moral, costumes e qualquer outra capacidade e hábito adquirido pelo homem como membro da sociedade." (TYLOR, I98I, p. 19) Assim, a educação, seja no seu aspecto substantivo (o que se aprende), seja no seu aspecto procedimental (como se ensina e como se pensa esse processo), é tanto cultura como parte do conhecimento do homem em sociedade como é também cultura em conformidade com o artigo $2 \mathrm{I} 6$ supracitado, ao incluir na definição de patrimônio cultural as formas

\footnotetext{
14 Tal tema foi objeto da pesquisa pós-doutoral desta autora, com bolsa PNPD-Capes em 2017, tema central do projeto de evento aprovado no Paep-Capes que resultou no livro Direitos sociais, educação e gestão pública: em homenagem a Anísio Teixeira, e também dos projetos oferecidos para Paraíba e Rio Grande do Norte vinculados ao Simec-Pradime: o curso de aperfeiçoamento para gestores municipais de educação, e depois o curso de especialização em Gestão da Educação Municipal, ambos aprovados, financiados e executados, formando cerca de 400 gestores, pelo Programa de Pós-Graduação em Ciências Jurídicas da UFPB (durante minha gestão como coordenadora) - único ofertado por um PPG em Direito no país - , que resultou numa excelente avaliação do PPGCJ na pontuação quadrienal pela Plataforma Sucupira da Capes (para coleta de dados e avaliação dos programas de pós-graduação) no critério "inserção social".
} 
de expressão (assim, a educação de um povo é fruto de sua história e mistura de raças (BRASIL, I988, art. 2I6, alínea I), os modos de criar, fazer e viver (BRASIL, I988, art. 2I6, alínea II), as criações científicas, artísticas e tecnológicas (BRASIL, I988, art. 2I6, alínea III), por exemplo.

Se a Constituição, no caput do artigo 216, destaca o conjunto de referências ligadas aos diferentes grupos formadores da sociedade brasileira, a educação é fruto legítimo dessa etnicidade.

$\mathrm{Na}$ história brasileira, um marco que reclama o destaque e percepção de aspectos estético-culturais até então obnubilados pela nossa própria cultura foi a Semana de Arte Moderna de 1922. Esta traz à cena o "Manifesto antropofágico", na sua pretensão de "deglutir as formas importadas para produzir uma arte e cultura genuinamente nacionais [..., e] inicia uma nova síntese cultural que procura abarcar as múltiplas faces da brasilidade. Trata-se de reinventar o país, a partir da valorização de um passado até então desprezado" (TORELLY, 20I2, p. 3).

Não obstante sua formação de jurista, é na atividade administrativa ligada à educação e no refletir sobre ela que Anísio Teixeira cria seu legado, que promove sua memória como pedagogo. Talvez do jurista aproveitasse a percepção dos direitos do homem, direitos sociais, direito à educação, direitos culturais, patrimônio cultural, dignidade humana, soberania nacional, deveres do Estado, mas esses temas jurídicos não precisam de um “juridiquês” verborrágico para se fazerem presentes no quadro teórico de Anísio Teixeira pelas lentes de um pedagogo.

Se no processo educativo está o ponto de partida para a garantia da própria democracia (TEIXEIRA, I967, p. 55-67), num momento em que a educação pública de qualidade e a própria vida democrática estão sob ameaça, a atualidade e urgência dessas ideias anisianas para a retomada das condições do nacional-desenvolvimentismo é a única direção em que se pode sonhar um futuro.

* Pós-doutorada (bolsa PNPD-Capes em 2017) com pesquisa sobre interfaces da Pós-Graduação em Direito e Educação Básica em atenção a metas da Capes como projetadas por Anísio Teixeira. Professora associada III no Centro de Ciências Jurídicas da Universidade Federal da Paraíba (CCJ-UFPB); Docente do mestrado e doutorado do Programa de Pós-Graduação em Ciências Jurídicas (PPGCJ) da UFPB e do Programa de Pós-Graduação em Direito da Universidade Federal de Pernambuco (PPGD-UFPE). Líder (CNPq) do Grupo de Pesquisa Realismo Jurídico. Pesquisadora do Grupo de Pesquisa Marxismo e Direito. Aprovada no Programa de Apoio a Eventos no País (PaepCapes) em 2017-2018 com projeto em homenagem a Anísio Teixeira que resultou em livro.

Tal artigo não teria esta forma final sem as contribuições valiosas de Ramiro Torres e Enoque Feitosa. É imperioso o registro do agradecimento.

Texto recebido em 3 de junho de 2021; aprovado em 7 de junho de 2021. 
AZEVEDO, Fernando de et al. Manifestos dos pioneiros da Educação Nova (1932) e dos educadores (1959). Recife: Fundação Joaquim Nabuco; Editora Massangana, 2010. (Coleção Educadores MEC.) Disponível em: <www.dominiopublico.gov.br/download/texto/me4707.pdf >. Acesso em: 12 jun. 2021.

BOIANOVSKY, Mauro; MONASTERIO, Leonardo. O encontro entre Douglass North e Celso Furtado em 1961: visões alternativas sobre a economia. Texto para Discussão, n. 2.341. Brasília; Rio de Janeiro: Ipea, 2017.

BRASIL. Constituição (1988). Constituição da República Federativa do Brasil. Brasília: Senado, 1988. Disponível em: <www.planalto.gov.br/ccivil_03/constituicao/constituicao.htm>. Acesso em: 13 jun. 2021.

COMISSÃO ANÍSIO TEIXEIRA DE MEMÓRIA E VERDADE. Relatório Setembro 2015. Brasília: UnB, 2015. Disponível em: <www.comissaoverdade.unb.br/images/docs/Relatorio_Comissao_da_Verdade. pdf>. Acesso em: 11 jun. 2021.

EDUCADORES brasileiros: Anísio Teixeira - educação não é privilégio. Direção: Mônica Simões. Rio de Janeiro: TV Escola, 2007. $44 \mathrm{~min}$. Disponivel em: <www.youtube.com/watch?v=ls-FoXhfM_Y>. Acesso em: 11 jun. 2021.

ESSAY. In: ESSENTIAL English dictionary. London: Chambers Harrap Publishers, 1999. p. 316.

FEITOSA, Enoque. Estado e sociedade civil em Gramsci: entre coerção e consentimento. In: Novo manual de ciência política. São Paulo: Malheiros, 2008. p. 307-320.

Ontologia em Álvaro Vieira Pinto e o direito. In: FREITAS, Lorena et al. (Org.). Direitos sociais, educação e gestão pública: em homenagem a Anísio Teixeira. Capes/Paep. Sedic: João Pessoa, 2018. p. 79-90.

FREITAS, Lorena; CECATO, Áurea. A educação como patrimônio cultural no quadro teórico de Anísio Teixeira. Cadernos de Dereito Actual, Santiago de Compostela, n. 5, p. 267-277, 2017. Disponível em: <www.cadernosdedereitoactual.es/ojs/index.php/cadernos/article/view/161>. Acesso em: 11 jun. 2021.

FREITAS, Lorena; FEITOSA, Enoque. Da intransponibilidade entre descrição e prescrição: um ensaio sobre pragmatismo e direito. Problemata, v. 8, n. 3, p. 160-171, 2017. Disponível em: <https://periodicos.ufpb.br/index.php/problemata/article/view/37471>. Acesso em: 20 maio 2021.

GRAMSCl, Antonio. Os intelectuais e a organização da cultura. Rio de Janeiro: Civilização Brasileira, 1968a.

Literatura e vida nacional. Rio de Janeiro: Civilização Brasileira, 1968b.

INEP. Arquivo histórico do Inep. Brasília: Inep, s.d. Disponível em: <http://arquivohistorico.inep.gov. br>. Acesso em: 20 maio 2021.

LIMA, Haroldo Borges Rodrigues. Haroldo Borges Rodrigues Lima I: depoimento, 2005. Rio de Janeiro: FGV-CPDOC, 2020. Disponível em: <www.fgv.br/cpdoc/historal/arq/Entrevista1418.pdf>. Acesso em: 20 maio 2021.

NUNES, Clarice. Anísio Teixeira. Recife: Fundação Joaquim Nabuco; Massangana, 2010. (Coleção Educadores.)

Anísio Teixeira entre nós: a defesa da educação como direito de todos. Educação \& Sociedade, v. 21, n. 73, n.p., dez. 2000. Disponível em: <www.scielo.br/j/es/a/tkVFzhPRWLjXZO89XcqdCB$\mathrm{D} /$ ?lang=pt>. Acesso em: 11 jun. 2021.

PINTO, Álvaro Vieira. O conceito de tecnologia. Rio de Janeiro: Contraponto, 2005. v. 1.

SAID, Mamede. Anísio Teixeira: a educação como instrumento de transformação social. In: FREITAS, Lorena et al. (Org.) Direitos sociais, educação e gestão pública: em homenagem a Anísio Teixeira. Capes-Paep. Sedic: João Pessoa, 2018. p. 11-24.

SAVIANI, Dermeval. História das ideias pedagógicas no Brasil. Campinas: Autores Associados, 
2007. (Coleção Memória da Educação.)

SMITH, Adam. Conferências sobre retórica e belas-letras. Rio de Janeiro: Topbooks, 2008.

SODRÉ, Nelson Werneck. Raízes históricas do nacionalismo brasileiro. In: SOUZA, Nilson de; CAMPOS, Rosanita. Pensamento nacional-desenvolvimentista. São Paulo: Anita Garibaldi; Fundação Maurício Grabois; Cátedra Claudio Campos, 2021. p. 143-161.

SUZUKI, Márcio. O ensaio e a arte de conversar. Posfácio. In: HUME, David. A arte de escrever ensaio. lluminuras: São Paulo, 2011. p. 287-332.

TEIXEIRA, Anísio. Administração pública brasileira e a educação. Revista Brasileira de Estudos Pedagógicos, Rio de Janeiro, v. 25, n. 63, p. 3-23, 1956 a.

A educação e a crise brasileira. Rio de Janeiro: Editora UFRJ, 2005.

Análise de sistemas e educação. Revista Brasileira de Estudos Pedagógicos, Rio de Janeiro, v. 59, n. 129, p. 57-59, jan.-mar. 1973.

A propósito da "Escola Única". Revista do Ensino, Salvador, v. 1, n. 3, p. 445-448, 1924.

Aspectos da reconstrução da Universidade Latino-Americana. Revista Brasileira de Estudos

Pedagógicos, Rio de Janeiro, v. 47, n. 105, p. 55-67, jan.-mar. 1967.

Autonomia para educação na Bahia. Revista Brasileira de Estudos Pedagógicos, Rio de Janeiro, v. 11, n. 29, p. 89-104, jul.-ago. 1947.

Bases da teoria lógica de Dewey. Revista Brasileira de Estudos Pedagógicos, Rio de Janeiro, v. 23, n. 57, p. 3-27, jan.-mar. 1955.

Centro Brasileiro de Pesquisas Educacionais. Revista Brasileira de Estudos Pedagógicos, Rio de Janeiro, v. 25, n. 61, p. 145-149, jan.-mar. 1956b.

Cultura e tecnologia. Revista Brasileira de Estudos Pedagógicos, Rio de Janeiro, v. 55, n. 121, p. 13-37, jan.-mar. 1971. dez. 1959.

Dewey e a filosofia da educação. Boletim Informativo Capes, Rio de Janeiro, n. 85, p. 1-2,

Educação e desenvolvimento. Revista Brasileira de Estudos Pedagógicos, Rio de Janeiro, v. 35, n. 81, p. 71-92, jan.-mar. 1961.

Educação e o mundo moderno. Rio de Janeiro: Editora UFRJ, 2006.

Educação é um direito. Rio de Janeiro: Editora UFRJ, 2009.

Educação no Brasil. Rio de Janeiro: Editora UFRJ, 2011.

1930.

Por que "escola nova"? Boletim da Associação Bahiana de Educação, Salvador, n. 1, p. 2-30,

TOLEDO, Caio Navarro de. Iseb: fábrica de ideologias. 2. ed. Campinas: Editora da Unicamp, 1997. (Série Pesquisas.)

TORELLY, Luiz P. P. Notas sobre a evolução do conceito de patrimônio cultural. In: Fórum Patrimônio, Belo Horizonte, v. 5, n. 2, s.p., jul.-dez. 2012.

TYLOR, Edward Burnett. Cultura primitiva. Madrid: Ayuso, 1981. v. 1. 